This item was submitted to Loughborough's Research Repository by the author.

Items in Figshare are protected by copyright, with all rights reserved, unless otherwise indicated.

\title{
Offering choices to people with intellectual disabilities: an interactional study
}

PLEASE CITE THE PUBLISHED VERSION

PUBLISHER

(C) Blackwell Publishing Ltd

VERSION

AM (Accepted Manuscript)

LICENCE

CC BY-NC-ND 4.0

REPOSITORY RECORD

Antaki, Charles, W.M.L. Finlay, Chris Walton, and L. Pate. 2019. "Offering Choices to People with Intellectual Disabilities: An Interactional Study". figshare. https://hdl.handle.net/2134/5438. 
This item was submitted to Loughborough's Institutional Repository (https://dspace.lboro.ac.uk/) by the author and is made available under the following Creative Commons Licence conditions.

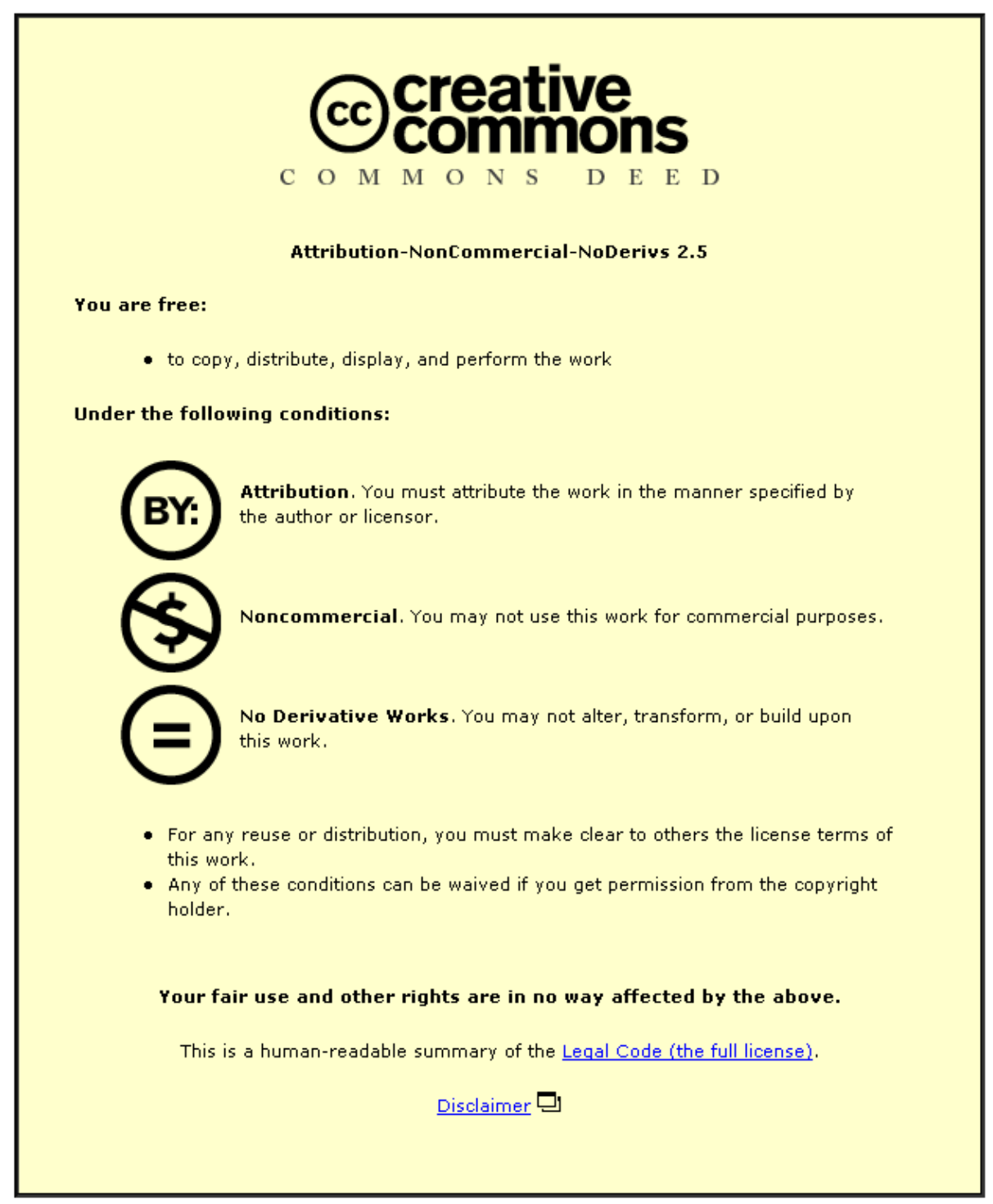

For the full text of this licence, please go to: http://creativecommons.org/licenses/by-nc-nd/2.5/ 


\title{
Offering choices to people with intellectual disabilities: an interactional study
}

Antaki, C.; Finlay, W.; Walton, C.; Pate, L.

JIDR, 2008

\begin{abstract}
$\underline{\text { Abstract }}$
At the level of policy recommendation, it is agreed that people with intellectual impairments ought to be given opportunities to make choices in their lives; indeed, in the UK, the Mental Capacity Act of 2005 enshrines such a right in law. However, at the level of practice, there is a dearth of evidence as to how choices are actually offered in everyday situations, which must hinder recommendations to change. This qualitative interactional study, based on video recordings in British residential homes, combines ethnography with the fine-grained methods of Conversation Analysis to identify some conversational practices that staff use to offer choices to residents with intellectual disabilities. We describe the unwanted consequences of some of these practices, and how the institutional imperative to solicit clear and decisive choice may sometimes succeed only in producing the opposite.
\end{abstract}




\section{Offering choices to people with intellectual disabilities: an interactional study}

For people with learning or intellectual disabilities, making choices is not easy - indeed, they may find it hard even to get the opportunity to make choices at all. Such limited access to choice alarms and concerns policy makers. In Britain, the Department of Health intervened to making the explicit recommendation, in an recent influential White Paper on services for people with intellectual disabilities (Department of Health, 2001) that they should be given more choice and control over their own lives. That led to the Mental Capacity Act (2005), which enshrines in law the right to make one's own decisions, whatever one's mental impairments.

But experience shows that putting systems in place to allow and encourage choice may be easier said than done (as noted, among others, by Beamer \& Brookes, 2001; Dowson, 1997; Edge, 2001; Harris, 2003; and Jenkinson, 1993). Support staff face a difficult task in working with people with very different communication abilities - differences which the staff may be inadequately trained to deal with. Offering people choices may conflict with staff members' responsibilities for health and safety, with meeting their institution's service targets, and with the pressing matter of getting jobs done within the allocated time on shift. These are important parts of the staff's day; indeed they will lose their job if these things are not done properly.

How the dilemma might be solved is not easy; one thing that the debate lacks, however, is an account of what actually happens in utterly mundane, routine examples of such

dilemmas. That is what this paper reports. How do staff manage the task of offering choices and issuing proposals to the residents? What, actually, are their routine conversational practices in offering choice, and what might be the unwanted consequences of those practices?

$\underline{\text { Data }}$ 
The data extracts presented here come from an ethnographic study of three residential services for people with intellectual impairment, located within a National Health Service Trust in the South of England. Over the course of nine months, one of the authors (CW) engaged with residents and staff, made ethnographic field notes of everyday interactions, and made video and audio recordings. The data we report here came from one home where residents had some verbal fluency. Permission to record and publish data was granted by all participants who appear in these extracts, and all names of speakers, and of individuals and places mentioned, have been changed.

\section{Participants}

Five men with intellectual disabilities (who we have called Dominic, Alec, Henry, Victor and Oliver) live in the home in question. Each of these men has been in receipt of residential care services for at least 30 years. In all cases the residents' files say only that each is diagnosed as having 'Learning Disabilities' (this label has the same meaning in the UK as 'intellectual disabilities' and 'mental retardation' in other countries) and in one case as having 'Learning Disabilities and Down's Syndrome'. All the residents require some level of support from members of staff to engage in activities ranging from intimate care, to cooking, to accessing services and resources in the community. They also require support to communicate with people outside the home (e.g. when shopping). No other, more detailed, clinical information, for example measures of the verbal or cognitive abilities of the residents, was available to the researchers.

\section{Sample of choice episodes}

In total, we identified over 120 examples in one home which could reasonably be described as occasions on which a member of staff offered a choice to a resident. But we warn against taking these numbers (roughly 120 occasions across about 10 hours of video records) to be even a crude index of the frequency with which such events happen throughout the day, since, although the researcher made sure to sample as wide a range of staff shifts, times of day, meals and the presence of residents, no pretence can be made that this was done systematically enough for the count to pass as a genuine survey of the 
frequency with which residents are offered choices. Nevertheless, it is safe to say that the densest volume of choice-offers were made, perhaps not surprisingly, at times deliberately structured around explicit recording of preferences and choices - meal planning, holiday planning and leisure planning, all of which occurred during scheduled house meetings around the kitchen table.

\section{Method}

Conversation Analysis' (CA's) strength is in approaching the recorded data with a range of analytical concepts to do with the organisation of talk (see ten Have, 1999, 2008): how one utterance projects a certain kind of next utterance; how its internal design achieves a certain social action; how an utterance can be marked as expected or unexpected, sufficient or insufficient, tentative or final, and so on. CA's sensitivity to the sequence of talk as the interaction unfolds arguably gives it an advantage over systems of contentanalysis which seek to identify given taxonomies of speech-types (open v. closed question, and so on). In what follows, then, we shall not be reporting the outcome of a coding system (compare the useful, but not interactionally specific, findings reported in, for example, McConkey, Morris and Purcell, 1999), but rather analysing the details of the exchanges between residents and staff as they play out in real time.

Conversation Analysis has been usefully applied in institutional settings involving people with various kinds of communication difficulty. Pertinently for the study we report here, CA has been used to open up the practices of staff supporting people with intellectual impairments in building social relationships (Antaki, Finlay, Jingree, and Walton, 2007), in encouraging residents to talk (Antaki, Finlay, and Walton, 2007), in playing a game (Finlay, Antaki, Walton and Stribling, 2008), in overlooking non-verbal communication (Finlay, Antaki and Walton, 2008) and in dealing with residents' refusals (Finlay, Walton and Antaki, 2008).

\section{$\underline{\text { Analysis }}$}


Our analysis is in two parts. First, we shall describe six apparently successful procedures that we saw the staff use, all of which are based on practices familiar from everyday conversation. The staff tailored these everyday routines so as to get the resident to make a choice, while apparently not offending against other, more managerial imperatives keeping a meeting on track, not losing the attention of other people in the interaction, not imposing unwelcome cognitive demands on the resident they're talking to, and so on. Then, in the second part of the analysis, we shall describe what we argue are some manifestly unwanted consequences of some of these practices - and how these might be avoided.

\section{A: Apparently successful ways to offer choice}

As we noted above, opportunities to offer the residents choices cropped up both casually (for example, in an episode of preparing food in the kitchen, a staff member might offer a resident a choice of which apron to wear), and in structured meetings on the agendas of which "choice" featured significantly (for example, weekly menu-planning meetings). Six conversational practices, which turn out to be a selection from a wider range of practices available in 'ordinary' conversation, tended to recur.

i. Two-option simple alternative in one question

ii. Open question + understanding check of answer

iii. Open question + immediate multiple-option alternatives

iv. Open question + immediate single option

v. Open question repaired to one-at-a-time alternatives

vi. Closed (yes/no) question

We shall take them in order, explaining and exemplifying each one, and adding a brief analysis of what is happening sequentially in the exchange. We shall also provide the reader with an example of the same format used in ordinary conversation, to push home the point that these resources are selections from the common stock of anyone in this (British English) language community. 


\section{i. Two-option simple alternative in one question.}

The basic format of this practice was for the staff member to present two alternatives in one utterance (without provision or expectation that the first be accepted or rejected before the second is presented). That basic format admitted variants, of which only two need concern us. The more conversational-sounding variant was simply to reel off the question as a continuous conjunctive sentence. For example, in VD-07, the staff member is about to pour out the juice at breakfast, and asks: Do you want to get the glasses or are you drinking them out of your mugs this morning? This conversational variant was quite common, and its format is of no special interest at this point (though later we will see what trouble sometimes followed when a resident gave an answer that the staff member felt he or she had to check or confirm).

Of more interest here is a variant that we saw used only by one staff member ("Dave"). He would, on occasion, present the resident with a question stem (e.g. which is better, ...., or which do you want, ....) followed by an unambiguous, two-option set of alternatives. This brought the choice into sharp relief. In the example we set out below, Dave is asking resident Dominic which of two different leisure activities he wants to go to in the coming week. Dave emphasises that there is more than one alternative by reinforcing his words with graphic physical tokens: his fists on the table.

Note on transcription: In the extract below, we have used a light version of standard CA notation to get across crucial features of the talk: overlap between speakers, gaze or action concurrent with the speech, pauses, sound-stretching, and emphasis. Square brackets indicate moments of overlap between different speakers, either in talk or gesture. For example, in the extract below Dave says 'Rose House' at the same time as tapping his left fist (lines $3 \& 4$ ). A glossary of the transcriptions conventions is given in the Appendix. All names of individuals and places have been changed.

Extract 1. VC-03; 11:19 minutes. Rose House or Pardew's? 


\begin{tabular}{|c|c|c|}
\hline$\rightarrow$ & Dave: & Which is $(0.8)$ [ which is better, \\
\hline 2 & & [((leans toward Dom. holding out left fist $))]$ \\
\hline $3 \rightarrow$ & & ] or [Pardew's. \\
\hline & & {$[(($ taps left fist twice $))] \quad[(($ taps right fist once $))]$} \\
\hline 5 & Dom: & ((points toward Dave's right fist)) \\
\hline 6 & Dave: & [Pardew’s is better? \\
\hline 7 & & [((taps right fist four times, whilst looking at Dom))] \\
\hline & Dom: & $(($ nods $))$ \\
\hline & Dave: & [((points to his left fist)) Rose House?] \\
\hline 10 & & [((shakes his head minimally)) \\
\hline 1 & Dom: & ((shakes his head and right hand)) \\
\hline 2 & Dave: & [No: \\
\hline 13 & & [((shakes his head))] \\
\hline 4 & Dave: & [Pardew’s \\
\hline 5 & & [((points to his right fist $))]$ \\
\hline 16 & Dom: & ((nods and points toward Dave's right fist)) \\
\hline 7 & Dave: & Okay. ((nods, picks up pen, leans back in chair and writes)) \\
\hline
\end{tabular}

The question stem in line 1 orients the resident to the upcoming choice (line 3). This is a highly recognisable choice-format in both 'ordinary' talk an in more institutionalised forms of soliciting preferences.

Although a 'normal' practice, this turns out to be a worthwhile help to people with a learning impairment, as it makes it easy to identify what, in the staff member's potentially complex utterance, counts as the choices on offer. That this staff member seems to have developed the practice himself - it is used by no other staff - is testament to his ingenuity and sensitivity to the residents' needs. We might also note that he makes the separation of choices more graphic by locating them physically as being (literally) on one hand or the other. This, too, is a welcome aid to clarity.

ii. Open question + understanding check 
A commonly used practice was to present the resident with a simple open question (such as "What would you like to do?" or "where do you want to go?") leaving space for an immediate answer. In principle, that is certainly consistent with a policy imperative to promote free choice. However, it was notable that if an answer did come, it was only infrequently accepted and recorded without further elaboration. This is a very different practice from that of the survey interviewers we mentioned above, who are mandated to accept any properly formatted answer and move on (Houtkoop-Steenstra, 2000), but is not unknown in ordinary conversation. More common was for the staff to check the answer in a series of confirmatory questions - that is, questions which presented for confirmation a candidate answer (Pomerantz, 1988), which had some relation to the resident's spoken or mimed utterance. In the example below, staff member Kath is asking residents, in turn, about what leisure activities they would like to pursue.

Extract 2. VC-17; 07:31 minutes.

$1 \rightarrow$ Kath: ((turns to Vic)) What about you Vic.

2 Vic: ((makes home sign for 'horse' with both hands, nods at Kath))

$3 \rightarrow$ Kath: [You want [ho:rse-riding ]

$4 \quad$ [((nods head once $))$ ]

5 Vic: [((nods at Kath, home signs 'horse'))]

The acceptability of this practice relies, of course, on the plausibility of the staff's interpretation of the resident's answer, whether spoken or (as in the case above) mimed. That, in turn, relies on the resident producing an answer which the staff can reasonably recognise or interpret. Although Kath here reads Vic's horse sign, we often observed situations where staff failed to recognize the resident's response on first attempt. Faced with unintelligible or non-answers, the staff faced the dilemma of repeating the open question again (possibly many times), or moving to the next kind of format (iii, below), which short-circuited the procedure by providing specific answer alternatives. Shortcircuiting what might be a lengthy process does solve one problem for staff - it allows them to dislodge an obstacle and move on with other, possibly pressing, business in hand 
- but inevitably it risks being seen as not giving the resident time to think and reflect. As ever, these are real dilemmas which staff must solve in real time. For reasons of space, we skip over open-question repeats - which could be very lengthy - and move to see these examples of explicit alternatives.

\section{iii. Open question + immediate multiple-option alternatives}

In this format, the staff member left no gap for the resident to answer an open question (e.g. what would you like to do or what do you want) before immediately (that is to say, without allowing a potential transition-relevant space to open up for the next speaker) providing a list of possible alternative answers.

Extract 3. VC-12; 38:58. Peaches

1 Tim: ((looks at Alec)) Alec ((looking down at the table))

$2 \rightarrow \quad$ what d'you want for pudding=look there's (.8)

3 pru:nes, peaches,

$4 \quad$ (1.0)

5 Tim: ((points at something on the table and looks at Kath))

$6 \quad{ }^{\circ}$ you haven’t got Angel Delight ${ }^{\circ}$ ((looks down at the table))

$7 \quad$ ((picks up packet and looks up holding packet))

8 Alec: [peaches Tim ]

$9 \quad$ [((taps tin of peaches $))]$

Notice, at the arrowed line, that the staff member (Tim) leaves no hearable gap between the end of the open question (what d'you want for pudding) and the immediate projection of a list of alternatives (look there's .....). Indeed, the absence of a gap where the clause end makes it possible requires us to mark the transcript with a "latch" symbol at that point (line 2), indicating that for the ordinary hearer the two words seem to run together, and in marked contrast to the .8 of a second gap once the new turn-construction unit (look there's prunes) has been launched. This buffering of the open-ended offer away from ready uptake seems to be successful, insofar as the resident (Alec) does (after Tim 
addresses an aside to the other member of staff) apparently opt for one of the alternatives (peaches Tim). However, this was not always the case and, indeed, this very episode mutates into a rather less satisfying exchange, which we shall come to later in section B.

\section{iv. Open question + immediate single option}

As above, in this variant the staff member left no gap for the resident to answer an open question. But here what the staff immediately provided was a single option, rather than two or more alternatives. In the extract below, for example, staff members Kath and Oonagh are asking residents about their holiday preferences. Oliver has a holiday brochure in front of him.

\section{Extract 4. VC-17, Beach}

1 Oliver: ((turns brochure round, points to a picture in the

$2 \quad$ brochure and looks up at Kath briefly))

3 Kath: [Y:::es ]

$4 \quad$ [((puts her hand on brochure $))$ ]

$5 \quad(.4)$

$6 \rightarrow$ Kath where do you want to go, on the beach?

7 Oliver: ((looks up at Kath))

8 Kath: ((taps brochure with fingers)) [(in) the beach, (1.0) ]

9 Oliver: [((looks down at brochure $))]$

10 Kath: is it,

11 Oliver: ((nods))

We can see in line 6 that Kath has interpreted Oliver's pointing as indicating some kind of choice, but rather than issuing a general enquiry with an open question, she bolts on a candidate answer without pause (presumably based on the picture he has pointed to). To this Oliver makes no unambiguous response (he merely looks up at Kath, without indicating assent or dissent). Kath then has the opportunity to put the choice more openly, but in fact she repeats the directive question/suggestion (line 8): the beach, and when this 
gets no obvious answer, she adds is it, as a further pursuit (line 10). Such tag questions strongly project agreement, and so makes it interactionally troublesome for the resident to demur. Nevertheless, if Kath's interpretation is correct (as it seems to be from Oliver's nod in line 11), then this is an efficient way of getting Oliver to indicate that this is indeed the holiday choice he has in mind.

\section{v. Open question reissued as one-at-a-time alternatives}

In this variant of the open question + elaboration format, the staff member presents the question stem as before but follows it up not with a single candidate answer (as Kath did above) but rather with a series of such candidates, in pursuit of a response (Pomerantz, 1984). In the example below, we join as staff-member Tim establishes, by use of a picture-card, that resident Victor wants to order curry for a forthcoming meal. Our interest is in how staff member Kath uses a series of alternatives to try to find out which kind. Note that she does not explicitly pronounce the question stem (which here would be something like which sort of curry,...), but assumes that Victor will understand from the context that that is what is in play.

Extract 5. VC-12, 20:07. Curry.

1 Tim: you want that one ((i.e. what's on the picture card))

2 Vic: ((nods and points to the picture))

3 Tim: ((withdraws picture, looks a way from Vic))(well) we'll take it as

$4 \quad{ }^{\circ}$ a curry then ${ }^{\circ}$

5 (1.5) ((Tim hands picture to Kath))

6 Kath: (Rice $>$ 'n c [ärots $<-$ ).

7 Vic: [yeheh,

$8 \rightarrow$ Kath [chịcken, or beef, (1.0) [or (.) lamb.

$9 \quad$ Vic: $\quad\left[{ }^{\circ}(\text { beeh- })^{\circ}\right.$

This offering alternatives in a series seem to be successful; at line 9, Victor does seem to come up with a decision (softly spoken, and not perfectly articulated, but hearable as 
being "beef"). However, as we observed above in extract 2, such apparent success may belie an underlying problem, and we shall re-visit this example later to see some potential dangers.

\section{vi. Closed question}

Offering a choice by asking a closed question could occur in any environment. But it was not always straightforwardly dealt with. Here is an example of a staff member, during a meal, asking an resident about an upcoming social event:

\section{Extract 6. VD4 1.40. Present?}

(Talk between other people round the table left out)

01 Dave ((to Alec)) Party tomorrow night?

02

[

$03 \quad$ [((Alec continues eating $))]$

04 Dave $\underline{\text { Alec. }}$

$05 \quad(2.0)$

06 Dave ((taps Alec on the hand, Alec turns to him)) Party t'morrow

07 night, [(Brian Connolly)

08. ? $[(\quad)$

$09 \quad(2.0)$

10 Dave we goin'ta buy him a present?

11 [ (4.0) ]

12 [((Alec looks a way from Dave))]

$13 \rightarrow$ Dave Are we buying him a present, yes or no.

14 Alec: ( )

$15 \quad(3.0)$

16 Alec: ( )

17 Dave Yep. 
Dave solicits Alec's choice of whether to go to a party, and whether to buy its host a present, by simple closed questions - but even such apparently simple formats may not always succeed. We see Dave require Alec to repair his apparent non-response in a subsequent turn. Inspection of such corpora as the Holt telephone conversation collection shows that re-issues of yes / no requests (among many other kinds of things that might misfire on first attempt) are common enough ${ }^{1}$. However, what may be unusual, and institutional, is the call for repair when there is no obvious extrinsic reason for the misfring.

More extended series of closed questions to solicit choice emerged, as we mentioned at the start of this section, in pre-planned meetings where part of the business was for each person, in turn, to make, or ratify, a choice. This led to a rapid series of round-the-table closed questions of each resident in turn. The extract below is taken from a necessarily longer episode. Dave is presenting, for confirmation, the minutes of the previous meeting.

Extract 7. VC-03 05.30 Happy with video?

1 Dave <All said they are still happy for Chris to come> a'we

2 still happy f'Chris to come, (.) and do the filming? (.)

$3 \rightarrow \quad$ [Oliver? still ] happy for Chris to come?=Victor, yeah?

$4 \quad$ [((mimes filming) $)]$

$5 \rightarrow \quad$ Henry, yeah?

6 Henry (Yeeh).

$7 \quad(.5)$

$8 \rightarrow$ Dave ((points at, and looks at, Dom)) Still happy, (1.0) with the video?

$9 \quad$ ((points at camera))

10 Dom ((nods))

$11 \rightarrow$ Dave ((turns to Alec)) Are you still happy with the video?

12 Alec weh-yeah.

13 Dave yep. ((turns to next item))

\footnotetext{
${ }^{1}$ We are grateful to an anonyous reviewer for this caution
} 
Such heavily directive solicitations of choice were perhaps understandable given the comparatively high predictability of the answers, and the fact that the question was understood not as a fresh one that required active consideration, but a routine one, the answer to which was already known (indeed, it was in the minutes) and only wanted confirmation. Such a coincidence of factors was highly institutional, and was only liable to happen in the formulaic, pre-planned setting of a routine agenda-led meeting.

\section{B. Some unwanted consequences of offering choices}

In the section above we listed six practices which could, in principle, lead to relatively unambiguous choices being made by the residents. In this section, we turn to exploring some possible unwanted consequences of those practices. Of course, such dangers lurk even when the formats are used when non-impaired people are offered choices, so it is not the formats which are themselves as it were pre-loaded with risk: it is the way, as we shall see, that the staff's agenda conflicted with the residents' ready answers that brought them both into troubled waters.

\section{(i) Some dangers of asking for repeated clarifications / checks in a series}

Any of the formats above could be succeeded, once an answer was given, by a series of questions from the staff, meant to check or clarify the resident's answer. Indeed, the question + multiple alternatives-in-a-series format (see the "shopping, bowling" example - extract 4 above) explicitly provided for such a sequence. However, such checks may have the unwanted consequence of inducing the resident to change their answer. After all, what seems to be the re-issue of a question may indicate that there was something wrong with the answer (see Houtkoop-Steenstra, 2000 for a full discussion). That danger is revealed in this simple episode. Staff member Tim and resident Alec are in the kitchen preparing food. Tim is asking Alec which potato peeler he wants to use.

Extract 8. VC-08; 04:12. Potato peeler.

1 Tim: Which one do you wanna use (0.2) thị:s one or 
2 [this one

$3 \rightarrow$ Alec: [That one that one ]

$4 \quad$ [((points toward peelers, which are out of shot $))]$

5 Tim: $\quad{ }^{\circ} \mathrm{Go}$ on ${ }^{\circ}$

$6 \rightarrow$ Alec: ((picks up one of two peelers now in shot and inspects it))

7 Tim: [Are you gonna use that one ]

$8 \quad$ [((points toward peeler Alec is holding)) ]

9 [or this one ]

10 [((points to peeler on the worktop))]

$11 \quad(.3)$

$12 \rightarrow$ Alec: $\quad>$ That one $<$ ((puts down first peeler and picks up the

13 other peeler))

14 Tim: ((turns a way)) $\left({ }^{\circ}\right.$ well y'go on $\left.{ }^{\circ}\right)$

One might wonder why it is that the staff member requires confirmation of what looks to be a simple and decisive choice. Perhaps Tim interprets Alec's inspection of the first peeler as some doubt or reluctance, which needs checking; or it may be that he has some ulterior motive (in fact, it turns out that the peelers are not equally good, and the second peeler is easier to use). One way or another, the effect is that Alec, taking the hint that his answer was wrong, "changes his mind" - we put the term in scare quotes - about his decision.

\section{(ii) Some dangers of offering a list of alternatives in one utterance}

The first danger we saw (above) was of repeated checks or alternatives in a series. The same danger applies when the alternatives are listed in one continuous utterance. Consider the example of an ostensibly good practice which we saw, in part, as Extract 3 in the list of 'good' practices above. Recall that the staff are trying to find out, in a series of alternatives, exactly which kind of food the resident wants to order. We join as staffmember Tim establishes that resident Victor wants curry. Our interest is in how staff member Kath tries to find out which kind of meat he wants in the curry. 
Extract 9. VC-12, 20:07. Curry (repeated and continued)

1 Tim: you want that one ((i.e. what's on the picture card))

2 Vic: ((nods and points to the picture))

3 Tim: ((withdraws picture, looks a way from Vic)) (well) we'll take it as

$4 \quad{ }^{\circ}$ a curry then ${ }^{\circ}$

$5 \quad$ (1.5) ((Tim hands picture to Kath))

6 Kath: (Rice $>$ 'n c [arrots $<-$ ).

7 Vic: [yeh,

$8 \rightarrow$ Kath [chicken, or beef, (1.0) [or (.) lämb.

$9 \quad$ Vic: $\quad\left[{ }^{\circ}(\text { beeh- })^{\circ}\right.$

10 Kath lamb.

$11 \rightarrow$ Vic: ((nodding)) lahh.

12

13 Kath: lamb.

14

(.5)

15 Kath: ((leaning head right)) or beef.

$16 \rightarrow$ Vic: $\quad\left(\left(\right.\right.$ nodding)) (beeh-) 9ahm ${ }^{\circ}$

17 Kath: ((leaning head left)) or chịcken,

$18 \rightarrow$ Vic: $\quad$ ((moves hand forward to point to picture)) (mickeh).

19 Kath: which meat do you want.

20 Vic: ((points to a different picture)) $\left({ }^{\circ}\right.$ mickeh $\left.^{\circ}\right)$.

21 Kath: chicken.

22 Vic: ((leans back)) yeh ((nods))

23 Kath: ${ }^{\circ}$ okay: ${ }^{\circ}($ (turns a way from Vic)

Kath holds a card for Vic to consult, but this card only shows a picture denoting "curry and rice". To find out which sort of curried dish Vic wants, she puts choices to him elliptically (chicken, or beef, or lamb), that is, presuming that he will take them to refer to the pre-established topic, instead of laying the choices out more fully (as, say: would you like chicken curry, or beef curry?). That in itself is not the problem here (though elliptical 
questions may pose difficulties when the stem of the question is more complicated, and its relation to the elaborations less obvious): the problem is that Kath's full utterance (a list construction; see Jefferson, 1990) only reaches its conclusion when all the items are named, while Vic is concerned to make his choice at the first desirable opportunity. So his nomination of beeh (beef) (line 9) is ignored as Kath presses on with her list.

The consequence of Kath ignoring Vic's legitimate first answer is that it makes his changed second answer (lamb) ambiguous. It might certainly be a positive choice of the new and final item in Kath's list. Alternatively, however, i f Vic has failed to appreciate that Kath meant to set all the options out before entertaining a decision, he might well infer that his choice of beef was not merely ignored, but actively rejected.

\section{(iii) Some dangers of applying a verbal test of knowledge}

One constant dilemma for staff is what to take as evidence for the resident having made an informed decision. On the one had, they have to respect what seems to be a wellformatted answer; on the other, they may harbour the doubt that the resident somehow doesn't "mean" it. Knowing whether a judgement is well or poorly grounded is a classical ethno-methodical problem for any pair of interlocutors, but here it plays out between people with very different rights to decide the matter.

To illustrate what we mean, we have chosen a very long extract (a fuller version of extract 2 above) which will show the twists and turns of the exchange as the participants try to establish some sort of basis for judging the soundness of the choice being made. The extract is too long to give in its entirety, so we will have to intervene with our gloss at various points. There are a variety of cards and packets on the table, and Alec is being asked to choose a dessert for a meal later in the week. Extract 3 above showed that Alec replied to Tim's question with the apparently well-formatted answer peaches Tim, reinforced by his tapping the can of peaches on the table. In spite of that, in a stretch we have to gloss, Tim offers him, in short order, semolina, Angel Delight (the brand name of a pudding made from powder), semolina again, and, going back to the very first item, prunes. Kath intervenes: 
Extract 9. VC-12; 38:58. Tim, Kath and Alec - choosing dessert (2)

1 Kath: Which one do you want Alec?

2 Alec: ((picks up a packet and holds it toward Kath)) that one

We see a familiar pattern; repeated questions - apparently to check his reply - have prompted Alec to change his choice; after the barrage of items from Tim, he now seems to have abandoned the can of peaches in favour of a dessert in a packet. Perhaps conscious that their own questioning tactics may have confused Alec, the staff show their concern that his choice be informed.

Extract 10. VC-12; 38:58. Tim, Kath and Alec - choosing dessert (3)

$1 \rightarrow$ Kath: What is it (1.0) what is it tell me what it is,

2 Dom: ((hands Alec another packet))

3 Alec: ((takes packet from Dom)) ask (Chris)(leans toward Chris))

$4 \quad$ ask who that is ((holds packet close to Chris's face))

5 Chris: [((reaches hand toward packet Alec is holding))]

6 Oliver: [((takes packet from Alec))

7 Kath: [n-you tell us what it is ]

$8 \quad$ [((nods head toward Alec) $)]$

9 (.4) [you've ma:::de it so many times before what is it. ]

$10 \quad$ [((shakes head whilst looking at Alec))

11 Alec: ((looks at packet then looks at the table)) (yeahrr,)

Of course, the staff could have tried other ways to unpick the problem of Alec's apparently inconsistent choices. They could have returned to his original choice and offered him to choose one from the two options he had chosen (as in extract 1), or deferred the matter until things had cooled down, and so on. What is remarkable is their insistence that it be the resident who provides the assurance that all is, epistemologically, well: 
Extract 11. VC-12; 38:58. Tim, Kath and Alec - choosing dessert (4)

$1 \rightarrow$ Kath: Alec (.) what is it

2 Alec: ((looks down at packet he is holding))

3

4 [ye:::h ]

$5 \rightarrow$ Kath: What's the picture of it (.4) tell me what's in- what it is.

6

7 Kath: [look at the picture, ]

$8 \quad$ [((head nod toward packet Kath wants Alec to name)) ]

$9 \quad$ Alec: ((picks up the packet and looks at it))

$10 \rightarrow$ Kath: Is it a a:pple, is it stra:wberry, is it ch [ocolate, ]

11 Alec:

[Straw::b'rries ] ((looking at

the packet he is holding))]

$13 \rightarrow$ Kath: It's strawberry is it?

14

$15 \rightarrow$ Kath: $\quad[>$ I don't think so=have another look, $<$ ]

16 Alec: [((puts packet down ]

17 ((picks up papers on table, leans forward and puts papers down))

$18 \rightarrow$ Kath: [Alec, (.8) AL:ec you need to know what you're choo:sing darling ]

19 Alec: [((moves other packets around on the table)) ]

20 ((picks up a different packet, looks at it then holds it toward Kath))

21 that one

This catechism in the arrowed lines only has the effect, in line 9, of causing Alec once again to choose a different alternative; at the end of the extract he picks up a still different packet of dessert mix and offers it to Kath. She resumes her epistemological checking in a further long spate, which we must gloss. Kath tries to get Alec not simply to affirm that he knows what he is choosing but that he can name it, that he has had it before, and so on. His answers do not satisfy her, and she pursues her questioning for a further round, which space does not permit us to detail. At the end of all this, Alec has offered four different 
dessert options as his choice (the tin of peaches; the first packet of dessert mix; the semolina; then the second, different packet of dessert mix). Only the last was accepted, with what seems like no greater certainty that he had chosen it "knowingly" than the very first.

\section{$\underline{\text { Discussion }}$}

Our aim in this article was to move from abstract principle to recorded interactional reality, and see how it was that people with intellectual impairments get offered routine choices by the care staff who support them. Our video records, from one British residential home for people with intellectual disabilities, identified six common conversational practices, all of which could, when deployed sensitively, encourage free and clear choice. But the very same practices could be a source of obscurity. In much of what we saw, staff either present options confusingly, or subject the resident's response to a set of steps involving clarification, translation, confirmation, or repetition before granting acceptance. And these steps may cause more problems than they solve.

Several clear recommendations follow from the examples we give in the paper. Offering a list of more than two alternatives verbally can sometimes result in confusion to all concerned. This may depend on the particular choice offered or on the individual who is being addressed. When there is no alternative to verbal presentation of multiple options, two strategies from our examples seemed useful: 1) finish with an open question that does not contain any of the options in it, or 2) if the person has named a small number of options, present just these two or three options and ask the person to select one. Simply asking for confirmation of the last option the person has named is the least useful strategy. With regards to asking a person to choose between two options, staff member Dave's strategy in extract one seems a good one. First he introduces the decision with a question stem which is separated from the options. After a pause he presents the two options, using physical cues (his fists) to represent each one. This allows the resident to either point or name their choice. When the choice is made, he checks by presenting the 
dispreferred option, then re-confirms by presenting the chosen option, again using both words and physical cues.

The staff face a constant dilemma in how to play off the benefits of pursuit (making the resident's choice public and accountable) against its dangers (inducing change in a wellgrounded first choice). Our impression is that the institutional imperative of having an acceptable working answer to an agenda question is what wins out; and nowhere is this better exemplified than in an episode in which resident Alec is faced with such a flurry of options, checks and clarifying questions about what sort of dessert to order that he opts for four different choices in the space of as many minutes. The key to the length of the exchange is given by the staff themselves: the institutional imperative is that the resident must be seen to make his choice accountably. In the words of one member of staff involved: Alec you need to know what you're choosing, darling.

We end with an observation, a point on which we can offer no hard and fast conclusion, but which is important in the drive to turn policy into practice. The dilemmas facing staff are real, and driven partly by matters on the ground - the approaching end of shift, the pressing need to record an answer, competing jobs around the dinner table and so on, not least of which is the residents' own frequent (but certainly not constant) lack of conventional conversational clarity. To some degree, and despite service-providers' official aspirations, such matters resist policy recommendations if they are phrased at the general level. But certain parameters could, in our judgement, be relaxed if they were to be translated into the local scene. The kind of evidence we see here ought to be helpful to policy makers and practitioners in finding ways to move from principle to practice. 


\section{$\underline{\text { References }}$}

Antaki, C. (1999) Assessing quality of life of persons with a learning disability: How setting lower standards may inflate well-being scores. Qualitative Health Research, $\underline{9}$, 437-454

Antaki, C, Finlay, W.M.L., Jingree, T and Walton: C (2007) "'The staff are your friends': conflicts between institutional discourse and practice". British Journal of Social Psychology, 46, 1-18

Antaki, C, Finlay, WML, Walton, C. (2007) Conversational shaping: staff-members' solicitation of talk from people with an intellectual impairment. Qualitative Heath Research, 17, 1403-414

Antaki, C. , Finlay, M, Sheridan, E, Jingree, T and Walton, (2006) C. Producing decisions in a self-advocacy group for people with a learning difficulty: two contrasting facilitator styles. Mental Retardation, 44, , 322-343.

Department of Health (2001). Valuing People. London: Her Majesty's Stationery Office

Beamer, S. \& Brookes, M. (2001) Making decisions: best practice and new ideas for supporting people with high support needs to make decisions. VIA: London

Department of Health (UK) (2001) Valuing People. London: HMSO

Dowson, S. (1997). Empowerment within services: a comfortable delusion. In P.

Ramcharan, G. Roberts, G. Grant \& J. Borland (eds) Empowerment in everyday life: learning disability. London: Jessica Kingsley

Edge, J. (2001) Who’s in control?: decision-making by people with learning difficulties who have high support needs. London: Values Into Action. 
Finlay, W M L, Antaki, C, Walton, C. On not being noticed: learning disabilities and the non-vocal register. Intellectual and Developmental Disabilities: 45, (2008) 227-245.

Finlay, W M L Antaki, C. and Walton, C. Saying no to the staff - an analysis of refusals in a home for people with severe communication difficulties. Sociology of Health and Illness, (2008), 30, 55-75.

Finlay, WML, Walton, C and Antaki, C (2008) Promoting choice and control in residential services for people with learning disabilities. Disability and Society, 23, 349360

Finlay, WML, Antaki, C. , Walton, C and Stribling, P. (2008) The dilemma for staff in "playing a game" with people with a profound intellectual disability. Sociology of Health and Illness, 30, 531-549

Harris, J. (2003) Time to make up your mind: why choosing is difficult. British Journal of Learning Disabilities, 31, 3-8.

Houtkoop-Steenstra, H (2000) Interaction and the Standardised Survey Interview. Cambridge: Cambridge University Press.

Jefferson, G (1990) List construction as a task and resource. In G Psathas (ed) Interaction Competence/. Washington, DC; University Press of America. pp 63-92

Jenkinson, J.C. (1993) Who shall decide? The relevance of theory and research to decision-making by people with an intellectual disability. Disability, Handicap and Society, 8, 361-375 
McConkey, R.M., Morris, I. \& Purcell, M. (1999) Communications between staff and adults with intellectual disabilities in naturally occurring settings. Journal of Intellectual Disability Research, 43, 194-205

Pomerantz, A. (1984). Pursuing a response. In J. M. Atkinson \& J. Heritage (Eds.), Structures of Social Action. Studies in conversational analysis (pp. 152-163). Cambridge: University Press.

Pomerantz, A. (1988) Offering a candidate answer. Communications Monographs 55:360-373.

Rapley. M (2004) The social construction of Intellectual disability. Cambridge, England: Cambridge University Press.

Rapley, M. and Antaki, C. (1996) A conversation analysis of the 'acquiescence' of people with learning disabilities. Journal of Community and Applied Psychology, $\underline{6}$, 371-391

ten Have, P., (1999 / 2nd ed 2008) Doing Conversation Analysis, London: Sage 


\section{$\underline{\text { Transcription Symbols }}$}

\begin{tabular}{|c|c|}
\hline$()$. & Just noticeable pause \\
\hline$(.3),(2.6)$ & Examples of timed pauses (seconds) \\
\hline word $[$ word & \\
\hline [word & Overlapping talk or actions. \\
\hline wor - & A dash shows a sharp cut-off \\
\hline wo: $r d$ & Colons show that the speaker has stretched the preceding sound. \\
\hline (words) & A guess at what might have been said if unclear \\
\hline$(\quad)$ & Unclear talk, sometimes susceptible to identification on repeated hearing. \\
\hline word, WORD & Underlined sounds are louder, capitals louder still \\
\hline${ }^{\circ}$ word ${ }^{\circ}$ & Material between "degree signs" is quiet \\
\hline$>$ word word< & Faster speech \\
\hline$\rightarrow$ & Analyst's signal of a significant line \\
\hline$(s n i f f))$ & Attempt at representing something hard, or impossible, to write phonetically \\
\hline
\end{tabular}

